\title{
Porokeratosis ptychotropica: a rare manifestation with typical histological exam*
}

\author{
John Verrinder Veasey ${ }^{1}$ \\ Rute Facchini Lellis ${ }^{1}$ \\ Thiago da Silveira Manzione ${ }^{1}$
}

\author{
Monique Coelho Dalapicola ${ }^{1}$ \\ Adriana Bittencourt Campaner ${ }^{1}$ \\ Maria Clarissa de Faria Soares Rodrigues ${ }^{1}$
}

DOI: http:/ /dx.doi.org/10.1590/abd1806-4841.20164397

\begin{abstract}
Porokeratosis is a disorder of epidermal keratinization characterized clinically by a distinctive ridge-like border, and histologically by cornoid lamellae. The known clinical variants of porokeratosis are: classic porokeratosis of Mibelli, disseminated superficial (actinic) porokeratosis (DSAP), porokeratosis palmaris et plantaris disseminata, linear porokeratosis and punctate porokeratosis. In 1995, a seventh form was described as porokeratosis ptychotropica: a verrucous form resembling psoriasis involving the gluteal cleft presenting on the histological exam multiple cornoid lamellae. There are very few reports in the literature of this clinical variant. The present study describes the case of a healthy male presenting gluteal hyperkeratotic plaques for 22 years. He had been to several dermatologists, none of them had achieved a definitive diagnosis. We present a typical clinical presentation and its dermoscopy findings, in addition to histological examination that confirmed the diagnosis.
\end{abstract} Keywords: Buttocks; Dermoscopy; Histology; Keratosis; Porokeratosis

\section{COMMUNICATION REPORT}

Male patient, 41 years old, hypertensive, in use of captopril and Ginkgo biloba, sought the dermatology service for dermatosis located in gluteal region for about 22 years, with progressive growth. He reported having previously sought other services and having received treatment for psoriasis and widespread warts, but without success.

At physical examination, he presented symmetrical skin lesions in the gluteal region, characterized by extensive erythematous to wine color plaques, with hyperkeratotic surface, precise edges and irregular contours (Figures 1 and 2). Dermoscopy showed prominent hyperkeratosis thoroughly, with well-defined borders and no evidence of other structures (Figure 3).
Facing the possible differential diagnoses of disseminated warts and psoriasis, we opted for a biopsy and immunosuppression research with serologic tests. Anatomopathologic results revealed the presence of multiple cornoid lamellae and intense hyperkeratosis (Figure 4). Serologic tests for hepatitis B and C, syphilis and HIV were negative.

\section{DISCUSSION}

In 1995, Lucker et al described the first case of porokeratosis ptychotropica using the Greek words ptyche (fold) and trope (a turning) to describe the flexural distribution of this condition. ${ }^{1}$ The presented clinical condition is characteristic of this disease; however, given its rarity, more common diagnoses should be excluded. ${ }^{1,2}$ 


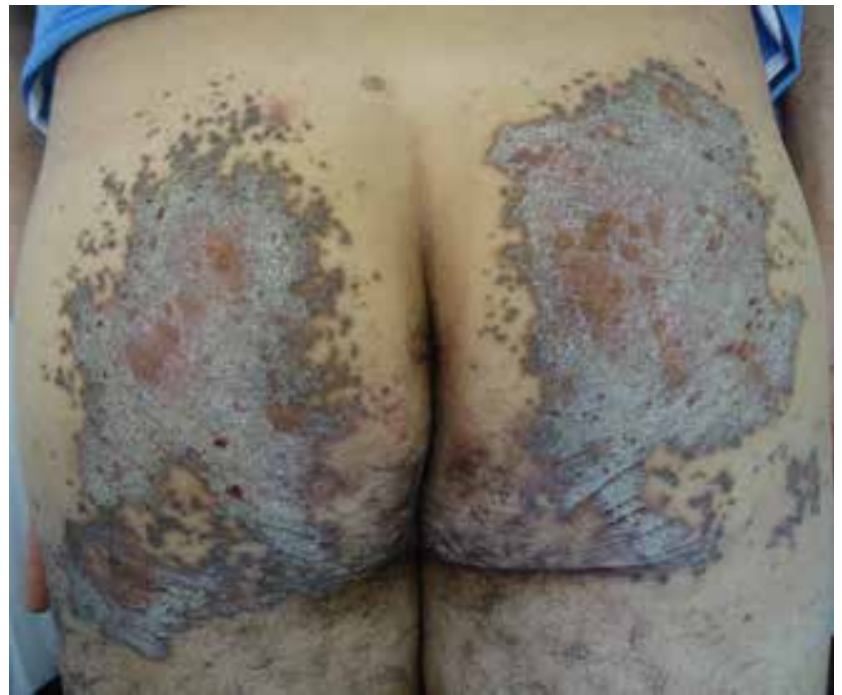

FIGURE 1: Gluteal lesions characterized by hyperkeratotic plaques

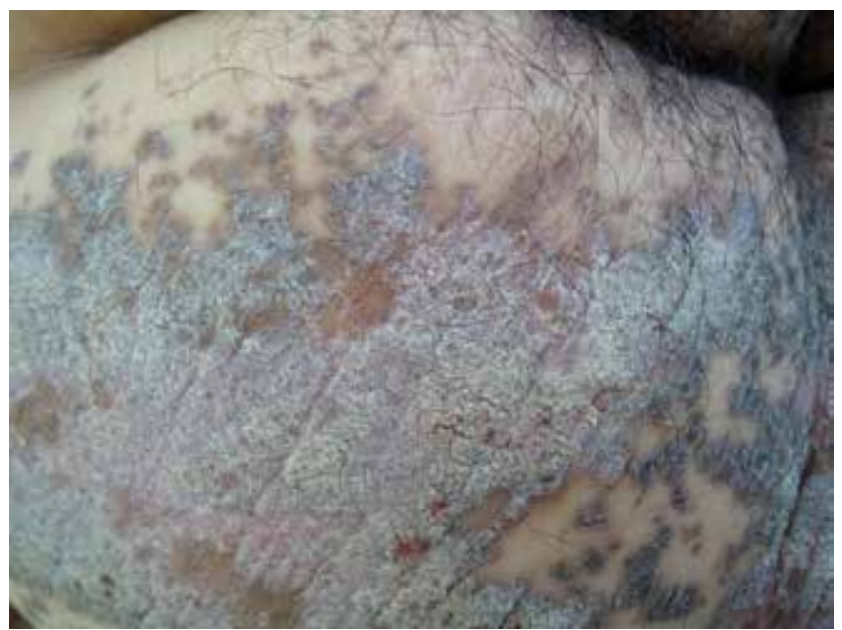

FIGURE 2: Detail of the periphery of the lesion in the left gluteus

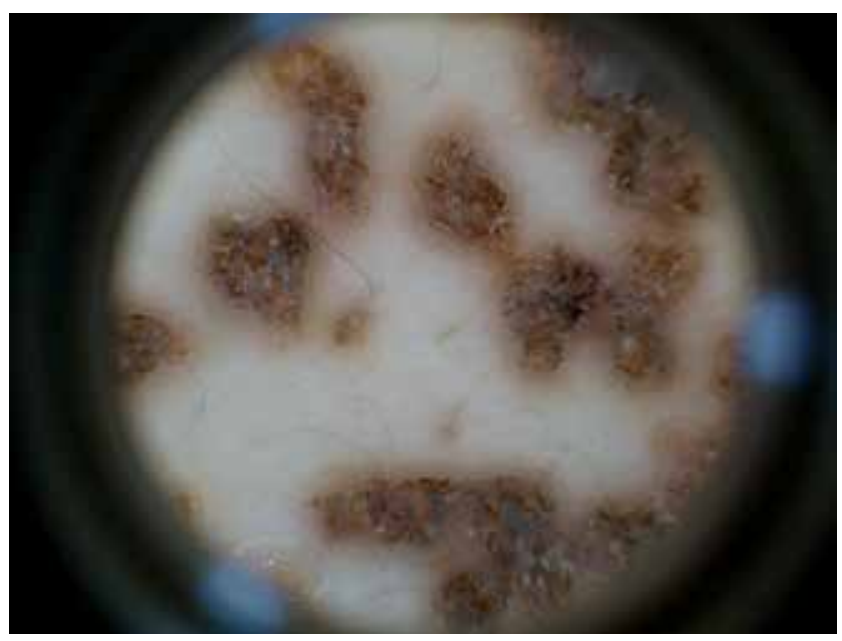

Figure 3: Contact dermoscopic examination in polarized light showing hyperkeratosis and well-defined edge

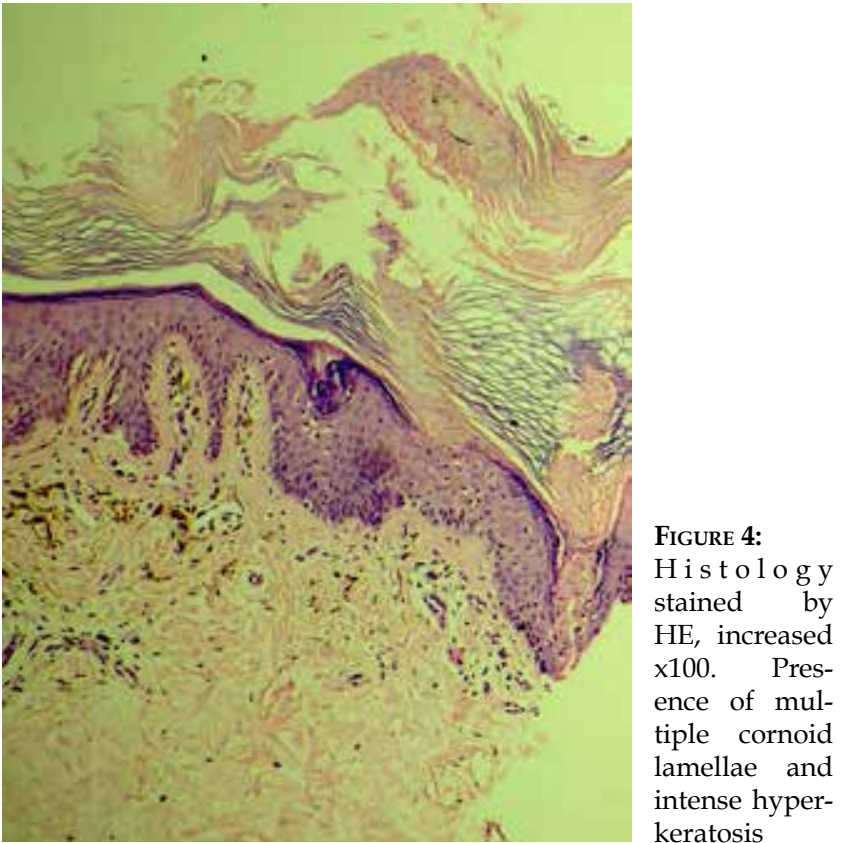

The main differential diagnoses are common warts and psoriasis. $^{2,3}$ In dermoscopy of verruca vulgaris, papillomatosis and dilation of the capillaries of the dermal papillae are observed, and hyperkeratosis may be evidenced according to the clinical presentation of the lesion. ${ }^{4}$ In the case of porokeratosis ptychotropica, only hyperkeratosis was observed and the other components of the viral warts were missing.

Histological examination was crucial for the diagnosis and exclusion of differential diagnoses. The absence of papillomatosis, dilation of dermal capillaries and koilocytosis ruled out viral warts. Regular acanthosis, Munro's microabscess or other characteristic findings of psoriasis also were not observed. On the other hand, multiple cornoid lamellae, establishing yielded the diagnosis diagnosis.

The patient was possibly immunocompetent due to nonreactive serology; however, it was not pursued further research into the possibility of other causes of immunosuppression, since the patient's immunity does not appear to interfere with the clinical manifestation of this form of porokeratosis. ${ }^{5}$

Several therapeutic modalities have been described, ranging from topical, such as imiquimod and tretinoin, to cryotherapy, photodynamic therapy, $\mathrm{CO}_{2}$ laser, surgical excision and oral retinoids. However, the condition has been reported to be unresponsive to these therapies. ${ }^{5}$

Due to the exuberant clinical condition, disease rarity and difficulty both in diagnosis and in treatment, the reported case is of great importance for the dermatological clinical practice, since it can be misdiagnosed as other common dermatoses or even sexually transmitted diseases.] 


\section{REFERENCES}

1. Lucker GP, Happle R, Steijlen PM.An unusual case of porokeratosis involving the natal cleft: porokeratosis ptychotropica? Br J Dermatol. 1995;132:150-1.

2. Broussard KC, Boyd A, Gloeckner Powers J. Thick intergluteal cleft and lower extremity plaques. JAMA Dermatol. 2013;149:1099-100.

3. Ferreira FR, Lessa PP, Alvarenga ML. Genitoglutea Iporokeratosis - Case report. An Bras Dermatol. 2013;88:438-40.

4. Veasey JV, Framil VMS, Nadal SR, Marta AC, Lellis RF. Genital warts: comparing clinical findings to dermatoscopic aspects, in vivo reflectance confocal features and histopathologic exam. An Bras Dermatol. 2014;89:141-4.

Takiguchi RH, White KP, White CR Jr, Simpson EL.Verrucous porokeratosis of the gluteal cleft (porokeratosisptychotropica): a rare disorder easily misdiagnosed. J CutanPathol. 2010;37:802-7.
MAILING ADDRESS:

John VerrinderVeasey

R. Dr. Cesário Mota Júnior, 112

Vila Buarque

01221-020 - São Paulo - SP

Brazil

Email:johnveasey@uol.com.br

How to cite this article: Veasey JV, Dalapicola MC, Lellis RF, Campaner AB, Manzione TS, Rodrigues MCFS. Porokeratosis ptychotropica: a rare manifestation with typical histological exam. An Bras Dermatol. 2016;91(4):496-8. 